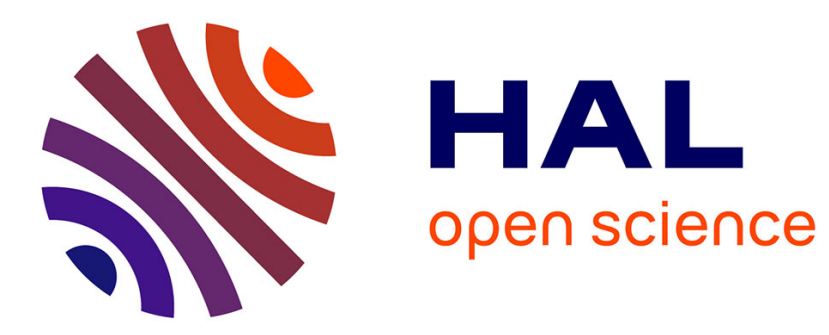

\title{
The protective role of immunoglobulins in fungal infections and inflammation
}

Sri Ramulu Elluru, Srini V Kaveri, Jagadeesh Bayry

\section{To cite this version:}

Sri Ramulu Elluru, Srini V Kaveri, Jagadeesh Bayry. The protective role of immunoglobulins in fungal infections and inflammation. Seminars in Immunopathology, 2014, 37 (2), pp.187-197. 10.1007/s00281-014-0466-0 . hal-01103153

\section{HAL Id: hal-01103153 https://hal.sorbonne-universite.fr/hal-01103153}

Submitted on 14 Jan 2015

HAL is a multi-disciplinary open access archive for the deposit and dissemination of scientific research documents, whether they are published or not. The documents may come from teaching and research institutions in France or abroad, or from public or private research centers.
L'archive ouverte pluridisciplinaire HAL, est destinée au dépôt et à la diffusion de documents scientifiques de niveau recherche, publiés ou non, émanant des établissements d'enseignement et de recherche français ou étrangers, des laboratoires publics ou privés. 


\title{
The protective role of immunoglobulins in fungal infections and inflammation
}

\author{
Sri Ramulu Elluru1, Srini V Kaveri ${ }^{2,3,4,5}$ and Jagadeesh Bayry ${ }^{2,3,4,5, *}$ \\ ${ }^{1}$ Department of Clinical and Experimental Medicine, Linköping University, \\ Linköping, Sweden \\ ${ }^{2}$ Centre de Recherche des Cordeliers, Equipe - Immunopathology and therapeutic \\ immunointervention, Institut National de la Santé et de la Recherche Médicale Unité \\ 1138, Paris, F-75006, France \\ ${ }^{3}$ Sorbonne Universités, UPMC Univ Paris 06, UMR S 1138, 15 rue de l’Ecole de \\ Médicine, Paris, F-75006, France \\ ${ }^{4}$ Université Paris Descartes, UMR S 1138, Paris, F-75006, France \\ ${ }^{5}$ International Associated Laboratory IMPACT (Institut National de la Santé et de la \\ Recherche Médicale, France - Indian Council of Medical Research, India), National \\ Institute of Immunohaematology, Mumbai, 400012, India
}

* Correspondence to: Jagadeesh Bayry, Institut National de la Santé et de la Recherche Médicale Unité 1138, Centre de Recherche des Cordeliers, 15 rue de l’Ecole de Médicine, Paris, F-75006, France. Tel: 00331442782 03; Fax: 00331 44278194

E-mail: jagadeesh.bayry@crc.jussieu.fr 


\begin{abstract}
Increased incidence of fungal infections in the immunocompromised individuals and fungi-mediated allergy and inflammatory conditions in immunocompetent individuals is a cause of concern. Consequently, there is a need for efficient therapeutic alternatives to treat fungal infections and inflammation. Several studies have demonstrated that antibodies or immunoglobulins have a role in restricting the fungal burden and their clearance. However, based on the data from monoclonal antibodies it is now evident that the efficacy of antibodies in fungal infections is dependent on epitope specificity, abundance of protective antibodies and their isotype. Antibodies confer protection against fungal infections by multiple mechanisms that include direct neutralization of fungi and their antigens, inhibition of growth of fungi, modification of gene expression, signaling and lipid metabolism, causing iron starvation, inhibition of polysaccharide release and biofilm formation. Antibodies promote opsonization of fungi and their phagocytosis, complement activation and antibody-dependent cell toxicity. Passive administration of specific protective monoclonal antibodies could prove to be beneficial in drug-resistance cases, to reduce the dosage and associated toxic symptoms of anti-fungal drugs. The longer half-life of the antibodies and flexibilities to modify their structure/forms are additional advantages. The clinical data obtained with two monoclonal antibodies should incite interests in translating pre-clinical success into the clinics. The anti-inflammatory and immunomodulatory role of antibodies in fungal inflammation could be exploited by intravenous immunoglobulin or IVIg.
\end{abstract}

Keywords: Fungi . Immunoglobulin . Inflammation . Aspergillus . Candida . Intravenous immunoglobulin . Therapy -Natural antibodies 


\section{Background}

Fungi are among the most common microbes encountered by mammalian hosts. Approximately, 1-10 fungal spores are ingested in each breath, making it a natural route of infection for most filamentous fungal pathogens. Medically important fungi include Aspergillus, Blastomyces, Candida, Coccidioides, Coccidioides, Cryptococcus, Histoplasma, Malassezia, Paracoccidioides and Pneumocystis [1-3]. Fungi are experts in sensing their surrounding environment and respond suitably to the different fluctuating environmental factors. Due to their acclimatization capabilities, fungi can interact with plants, animals and humans and establish symbiotic, commensal, latent or pathogenic relationships. For example, Candida albicans are commensal organisms in humans until the host becomes immune deficient, which can lead to life-threatening disease [4]. Omics-based approaches have revealed a link between fungal metabolism, morphogenesis and response to stress during adaptation to the host environment. These processes not only enhance fungal virulence but also provide opportunities for identifying potential therapeutic targets [5].

Many fungal pathogens as well as commensal fungi have co-evolved with their mammalian hosts over millions of years. This shows that fungi have developed effective and complex strategies to antagonize immune responses in the host. One recent report shows that air borne fungal spores of Aspergillus fumigatus evade the innate immune recognition and immune responses by expressing surface "rodelt layer" $[6,7]$. This layer is composed of hydrophobic RodA protein covalently bound to the conidial cell wall through glycosylphosphotidylionositol remnants. RodA extracted from conidia of $A$. fumigatus was immunologically inert and did not induce 
dendritic cell (DC) or alveolar macrophage maturation and activation. The disruption of this 'rodlet layer' chemically (using hydrofluoric acid), genetically ( $\triangle \operatorname{rod} A$ mutant) or biologically (germination) resulted in a conidial morphotype that induce immune activation. These observations show that the fungal pathogens have immune evasive mechanisms.

Innate immune responses are the first line of defense against fungal infections that lay foundation for the long lasting, more specific and effective adaptive immune responses. The fungal pathogen-associated molecular patterns (PAMPs) such as heatshock protein 60 (Hsp60), $\beta$-glucans, phospholipomannan, O-linked mannans, zymosan and fungal DNA are recognized by various pattern recognition receptors that include toll-like receptors (TLRs) (such as TLR 2, 4 and TLR9) and C-type lectin receptors (such as Dectin-1 and DC-SIGN) [8-10]. These detection mechanisms are also complemented by other defense mechanisms such as microbial antagonism, defensins, collectins and complement system.

The detection of fungal pathogens by phagocytes especially macrophages and DCs initiate downstream intracellular events that activate immune responses resulting in efficient clearance of fungi through phagocytosis and direct pathogen killing. Neutrophils play a key role in clearing hyphae, the tissue-invasive form of molds. DCs migrate to secondary lymphoid tissues and polarize diverse $\mathrm{CD} 4^{+}$T-cell ( $\mathrm{T}$ helper, Th) responses including Th1, Th2, Th17, and regulatory $\mathrm{T}$ (Treg) cell responses. This has been shown in case of Histoplasma capsulatum, Cryptococcus neoformans, C. albicans and A. fumigatus. The Th cells in turn direct B cells to produce antigen-specific antibodies that mediate humoral immunity. 
Role of humoral immune response in the protection against fungal infections: data from experimental models

Antibodies or immunoglobulins (Igs) are glycoproteins and one of the vital components of the immune system. Five classes or isotypes of antibodies have been identified that include IgG, IgM, IgA, IgE and IgD and their prevalence in the blood in the order of $\operatorname{IgG}>\operatorname{Ig} A>\operatorname{Ig} M>\operatorname{IgD}>\operatorname{IgE}$. Further IgG is divided into four subclasses such as IgG1, IgG2, IgG3 and IgG4 in human and IgG1, IgG2a, IgG2b and IgG3 in mice. IgA is most abundant antibody at mucosa and is divided into IgA1 and IgA2. Studies to prove the beneficial effects of antibodies in the protection against fungal infections have mostly came from in vivo studies in experimental models. These data suggest that antibodies provide protection against fungal infections via several and possibly interdependent mechanisms. In fact, antibodies are well known effector molecules of the adaptive immune system and neutralize the pathogens and their derived molecules in part through activation of the complement. In addition, they also exert regulatory role in the activation of innate immune cells by signaling via diverse Fc receptors. However, initial studies to understand the role of antibodies in antifungal immunity were largely inconclusive. These inconclusive reports could be due to occurrence of insufficient proportion of protective antibodies in the serum that are capable of clearing fungal infection. On the other hand, there could be inhibitory antibodies that neutralize the effect of protective antibodies [11, 12].

Several reports demonstrated that natural antibodies have an important role in the defense against fungal infection. In fact, administration of normal mice serum to $\mu \mathrm{MT}$ mice was shown to restrict the fungal growth in various models [13-16]. Natural 
antibodies are polyreactive, generally germ-line encoded and are characterized by low to medium affinity. Natural antibodies belong to IgM, IgA and IgG classes and are produced mainly by B1 cells [17-23]. A substantial fraction of serum antibodies from naive mice recognize fungal antigens including C. albicans [24, 25]. Further, passive administration of a monoclonal natural IgM antibody 3B4 recognizing self-antigen keratin and germ tubes of C. albicans, protected mice from C. albicans-induced death. The anti-fungal mechanisms of this natural antibody include direct suppression of germ tube formation and enhancing the macrophage-mediated phagocytosis of candida by opsonization [24, 26] (Fig. 1). In line with these observations, murine studies have shown that administration of opsonizing antibodies results in protection against invasive candidiasis $[27,28]$ although beneficial effects could not be observed in vaginal candidiasis [29].

Natural IgM are important for the resistance to $C$. neoformans and Pneumocystis murina in mice by diverse mechanisms. It was proposed that natural IgM enhance the recruitment of macrophages to the site of infection and phagocytosis of fungi; guide the recognition of fungal antigens by DCs and their migration to draining lymph nodes; and support B cell class-switch by helping differentiation of Th2 cells [30, 31]. In line with these observations, mice with X-linked immunodeficiency that have significantly lower levels of IgM displayed higher susceptibility to C. neoformans infection [32].

B-cell depleted mice show higher susceptibility to systemic candidiasis [33]. Systemic challenge of C. albicans in athymic mice [34], severe combined immunodeficiency (SCID) mice [35] and antibody deficient CBA/N mice lacking 
Lyb-5 B cells [36] showed that humoral immune responses play an important role in conferring protection against systemic candidiasis. Further, studies in B-cell knockout $\left(\mathrm{J}_{\mathrm{H}} \mathrm{D} \mu \mathrm{KO}\right)$ mice have shown that these mice are susceptible to experimental systemic candidiasis but resistant to mucosal and systemic candidiasis of endogenous origin [37]. These $\mathrm{J}_{\mathrm{H}} \mathrm{D}$ mice lacked circulating $\mathrm{B}$ cells or secretory antibodies due to disruption of immunoglobulin gene $\mathrm{J}_{\mathrm{H}}$ that arrests $\mathrm{B}$ cell development in the bone marrow. After oral immunization, these mice developed protective immunity to intravenous challenge. However, the mice showed colonization of C. albicans in the gut, indicating that the mode of infection does influence the outcome of immune responses by the host.

A report by Romani and colleagues reveals that antibodies have a critical role in the generation of memory anti-fungal immunity [16]. By evaluating the susceptibility of wild-type and B-deficient ( $\mu \mathrm{MT})$ mice to C. albicans or A. fumigatus infections by intravenous or intra-tracheal route respectively, they found that $\mu \mathrm{MT}$ mice could efficiently limit the fungal growth both upon primary and the secondary infections. Their results thus point out that Th1 cells are important to mediate protective immunity to these two fungal pathogens. However, $\mu \mathrm{MT}$ mice were incapable of surviving the re-infection with C. albicans. These results thus indicated that although the resistance to Aspergillus is independent of B cells and antibodies, protection against Candida appears to be mediated both by antibody-dependent and independent mechanisms [16]. Administration of normal mice serum to $\mu \mathrm{MT}$ mice further restricted the fungal growth, thus confirming that antibodies do have a role in restricting the fungal burden and in the clearance of pathogens, but as discussed later, 
their efficacy might be dependent on epitope specificity, abundance of protective antibodies and their isotype.

The findings of Romani and colleagues also suggest that the functions of antibodies in the protection against fungal infections might go beyond neutralization of pathogens, opsonization, antibody-dependent cytotoxicity or preventing adherence [16, 38] (Fig. 1). Thus, they identified a novel mechanism through which antibodies might participate in the protective immunity to Candida infections. It is known that circulating antibodies and B cells have remarkable ability to modulate the immune responses by regulating the functions of antigen presenting cells such as DCs [39-46]. Romani and colleagues reported that the inability of $\mu \mathrm{MT}$ mice to survive re-infection with C. albicans was associated with failure to generate IL-10-producing $\mathrm{CD} 4{ }^{+} \mathrm{CD} 25^{+}$ Tregs. Interestingly, antifungal opsonizing antibodies could restore IL-10 production in DCs indicating that antibodies could limit the exaggerated inflammatory responses to fungal infections and might educate the DCs for the development of long-lasting anti-fungal immunity [16] (Fig. 1).

In experimental paracoccidioidomycosis, a chronic granulomatous disease caused by thermally dimorphic fungi Paracoccidioides brasiliensis, circulating normal antibodies were shown to control $P$. brasiliensis growth and organization of the granulomatous lesions by regulating the infiltration of inflammatory cells [47].

Several reports also demonstrate that protective anti-fungal antibody responses could be induced in mice by vaccination with appropriate fungal antigens. Thus, vaccination with a liposomal-mannan admixture mediated antibody-dependent 
protection against C. albicans [14]. Importantly, synthetic glycopeptide vaccines that combine $\beta$-mannan and peptide epitopes (corresponding to those proteins expressed during human candidiasis and their cell wall association) also induced high titred antibodies to $\beta$-mannan and test antigens that include fructose-bisphosphate aldolaseFba, methyltetrahydropteroyltriglutamate-Met6 and hyphal wall protein-1. In addition, these antibodies rendered protection against experimental disseminated candidiasis following DC vaccination approach [48]. Further, passive transfer of immune sera either from peptide (Fba)-vaccinated mice or glycol-peptide ([ $\beta$ (Man) $\left.)_{3}\right]$-Fba)-vaccinated mice, conferred protection in naïve mice [49, 50]. Similarly, vaccination with other antigens was also shown to elicit protective antibody responses. A glycol-conjugate vaccine consisting of laminarin, a $\beta$-glucan from Laminaria digitata, and diphtheria toxoid CRM197 (Lam-CRM conjugate) protected mice against $A$. fumigatus and $C$. albicans by eliciting anti- $\beta-1,3$-glucan antibodies $[51,52]$. Intravaginal immunization with secreted aspartic proteases family (Sap2t) of C. albicans elicited protective mucosal IgG and IgA antibodies to Sap2t. Passive transfer of these antibodies or anti-Sap2t IgM and IgG monoclonal antibodies protected mice against vaginal candidiasis [53]. A virosomal vaccine containing Sap2t also induced similar immune responses and protection against vaginal candidiasis [54]. In line with these reports, immunization with purified or recombinant major surface glycoprotein of Pneumocystis carinii elicited protective humoral and cellular responses in rats [55]. These data thus suggested that abundance of protective antibodies is the key factor that determines the role of antibodies in the protection against fungal infections. 
DNA vaccination strategy was also explored for eliciting protective antibody response to fungal pathogens. Pneumocystis pneumonia infection is the most prevalent respiratory pathogen of AIDS patients and the options for immunotherapy have been limited given the poor $\mathrm{CD}^{+} \mathrm{T}$ cell immune responses. DNA vaccination with a Pneumocystis antigen, kexin linked to CD40 ligand, induced strong antibody response in mice, and that B cells or IgG from vaccinated mice were highly protective upon adoptive transfer $[56,57]$. This approach is highly desirable for patients who have $\mathrm{CD} 4^{+}$deficiency or dysfunction as this method could induce protective humoral responses independent of $\mathrm{CD} 4^{+} \mathrm{T}$ cells.

\section{Demonstration of protective role of antibodies in fungal infections by using monoclonal antibodies}

As relative abundance of protective specific antibodies was postulated as one of the factors that determine the protection afforded by circulating antibodies, various groups have evaluated this hypothesis by using monoclonal antibodies (MAbs). Most of the protective antibodies described to date recognize surface molecules that include, but not limited to glucans, mannans, and glucuronoxylomannans. In addition, proteins and glycolipids could also induce protective antibodies upon immunization.

By using C. neoformans capsular glucuronoxylomannan-specific murine MAbs, Casadevall and colleagues compared the protective capacities of various isoforms of antibodies upon passive transfer to lethally infected mice. They found that on a weight basis, IgA isotype antibody was most effective as compared to IgG1> IgM> IgG3. However, IgA has a shorter half-life than IgG1 in the circulation and hence more IgA antibodies would be required for the protective effects. Therefore, 
authors further performed the experiments by using antibody concentrations that closely mimics in vivo situation and found that IgG1 was more effective than IgA in conferring the protection against challenge [15]. In addition, other reports also confirmed the therapeutic potential of murine IgG1 MAb to capsular polysaccharide (CNPS), IgM MAb that binds to melanin and murine IgG2b MAb to glucosylceramide and $\beta$-glucan (laminarin) of $C$. neoformans [58-61].

The subclass of IgG also plays an important role in the protection against $C$. neoformans. The relative efficacy of IgG subclass antibodies was in the order of IgG1, IgG2a, and IgG2b 》 IgG3. Switching from IgG3 to IgG1 converted a nonprotective glucuronoxylomannan-reactive MAb into a protective antibody [62, 63]. Thus these data indicated that by simple isotype/subclass switching, a nonprotective antibody could be converted into a protective antibody and hence suggesting that those non-protective antibodies reported for fungal infections should be re-examined for the isotype. These $C$. neoformans protective glucuronoxylomannan-specific IgG MAbs seem to work in cooperation with nitric oxide, and both Th1 and Th2 cytokines $[64,65]$. In addition, binding of protective glucuronoxylomannan-reactive 18B78 IgG MAb and IgM MAbs (12A1 and 13F1) to C. neoformans also modifies the gene expression of the fungi, phosphorylation of proteins and lipid metabolism [66]. (Fig. 1) The complement component C3 was found to be dispensable for the protection by these IgGs [67]. In addition, mouse background also shown to influence the protection given by IgG subclass antibodies [68] thus underscoring the complex relationship between the cellular and humoral components of the immune system. Further studies from the same group revealed that epitope specificity of the MAbs is the critical factor that determines the serotype- 
specific protection rendered by the anti-C. neoformans MAbs and to confer protection against distinct serotypes of C. neoformans [69].

Han et al., showed that transfer of $\beta$-1, 2-mannotriose [ $\beta$-(Man) $\left.)_{3}\right]$-specific IgM MAbs enhance the resistance to disseminated candidiasis in normal, SCID and neutropenic mice, and to vaginal infection $[14,70,71]$ and was dependent on the specificity of the antigens but independent of isotype (IgM or IgG3) of antibodies [72]. Structural analysis revealed that internal antigenic determinants dominate recognition of $\beta$-(Man) $)_{3}$ by IgG3 MAb [73]. $\beta$-mannan-specific IgM MAb could also reduce the dose of amphotericin $\mathrm{B}$ when used in combination in experimental candidiasis [74]. In contrast to C. neoformans-specific MAbs, complement was found to be essential for the protection by $C$. albicans $\beta$-mannan-specific IgM and IgG3 MAbs and was associated with enhanced phagocytosis and killing of the yeast cells by phagocytic cells $[75,76]$ (Fig. 1). These results thus suggest that the mechanisms of anti-fungal antibodies might also depend on the fungal species and epitope specificity of the antibodies and that a generalized mechanism cannot be drawn.

An IgM MAb C7 that reacts with Als3p and enolase of C. albicans cell wall exerted three anti-candida actions such as candidacidal activity and inhibition of both adhesion and filamentation [77]. Subsequently it was found that the candidacidal activity of this MAb was linked to interference with iron acquisition by C. albicans [78] (Fig. 1). Of note, MAb C7 also showed reactivity against several species of Candida as well as in C. neoformans, Scedosporium prolificans and A. fumigatus thus pointing towards broad-spectrum activities of this antibody [78]. 
Compared to Candida and Cryptococcus, studies on the development of therapeutic MAbs to A. fumigatus are limited. An A. fumigatus-specific IgG1 MAb directed against cell wall glycoprotein of $A$. fumigatus exhibited protection against experimental aspergillosis in mice and significantly reduced the fungal load in the kidneys. The protection by this MAb might be due to its effects on germination of $A$. fumigatus [79]. The same group also developed an IgM MAb against immunodominant catalase B of $A$. fumigatus that exerted anti-A. fumigatus activities in vitro [80]. In a murine pulmonary aspergillosis model, A. fumigatus-specific IgM MAb-alliinase conjugate enhanced survival of immunosuppressed mice by causing specific killing of $A$. fumigatus without damaging the lung tissue [81].

IgG2a and IgG2b MAbs to gp43 of $P$. brasiliensis were shown to reduce fungal burden and was associated with the enhanced phagocytosis of P. brasiliensis by macrophages leading to increased nitric oxide production [82]. Prophylaxis passive intranasal administration of anti-glycoprotein A IgM or IgG1 switch variant MAb protected against murine $P$. carinii [83]. Further studies revealed that complement was required for the protection conferred by anti- P. carinii IgG1 antibodies [84].

Passive transfer of cell surface histone-like protein-specific IgM MAbs protected the mice against Histoplasma capsulatum by altering the intracellular fate of the fungus in the macrophages in a complement receptor 3-dependent process [85, 86]. This protection was associated with the enhanced IL-4, IL-6 and IFN- $\gamma$ in the lungs either on day 2 or day 7 post-infection. Similar to this report, passive transfer of H. capsulatum Hsp60-specific protective IgG1 and IgG2a MAbs significantly sustained the survival of mice infected with $H$. capsulatum. Administration of these 
MAbs could alter the pathogenesis $H$. capsulatum by modulating its intracellular fate and by significantly boosting Th1 cytokine responses such as IL-2, IL-12, IFN- $\gamma$ and TNF- $\alpha$ but not IL-4 in various organs either at day 7 or day 14 post infection [87]. Thus, enhancement of Th1 cytokine responses and modulation of intracellular fate of the fungus seems to be common factors associated with protection rendered by $H$. capsulatum MAbs. However, the regulation of cytokine responses might be dependent either on isotype of MAb or time-point of analysis.

\section{Role of antibodies in the protection against fungal infections: Data from human studies}

Normal human serum or repertoire contains natural antibodies to various pathogens. Candidal mannan-specific human IgG antibodies from normal human serum were shown to mediate classical complement pathway initiation [88]. Affinity purified natural mannan-specific human IgG displayed prozone-like effect and hence therapeutic use of monoclonal version of these natural IgGs requires careful dose titration studies [89]. A full-length human recombinant anti-mannan IgG1 (M1g1) was generated from anti-mannan Fab that was isolated from a phage Fab display combinatorial library containing Fab genes of bone marrow lymphocytes [90]. M1g1 activated complement pathway, enhanced phagocytosis and phagocytic killing of $C$. albicans by murine macrophages and rendered resistance to disseminated candidiasis in mice [90]. The complement activation and deposition of C3 on C. albicans by M1g1 could be independent of Fc-region as Fab fragments could activate alternative pathway to initiate C3 deposition [91]. Natural antibodies that react with candida antigens are also part of mucosal immunoglobulin repertoire wherein IgA from saliva 
were shown to recognize Candida antigens such as phosphoglycerate kinase and fructose bisphosphate aldolase [92].

Confirming the experimental studies on the role of immunoglobulins and B cells in the protection against fungal infection, a primary hepatic invasive aspergillosis with progression has been reported in a patient following rituximab therapy for a post transplantation lymphoproliferative disorder [93]. This report was further substantiated by another report wherein rituximab therapy was significantly associated with increased risk for invasive aspergillosis in patients with lymphoproliferative diseases after autologous hematopoietic stem cell transplantation [94].

Though, many break-through studies have dissected the role of antibodies in anti-fungal immunity, the translation of these pre-clinical studies to patients is still under progress. The presence of specific antibodies in patients with progressive fungal infections has provided evidence against a protective role of antibodies in fungal infections. Also, it has been shown that naturally acquired antibodies develop during infancy to C. albicans and in early childhood to C. neoformans [95]. However, the individuals still could not fight against fungal infections indicating that the presence of antibodies does not necessarily prevent fungal infections. Based on the reports from experimental studies, it is now clear that these patients' data might not reveal fundamental incapacity of antibodies to protect against fungal infections rather point towards inadequate amounts of protective antibody and/or the concurrent presence of both protective and non-protective antibodies. In fact, higher levels of IgG protective antibodies including those against Met6p, Pgk1p and Hsp90 are 
associated with good-prognosis in invasive candidiasis patients [96]. Another report indicated that patients who survived candidiasis display amplified antibody reactivity towards C-terminal epitope of mp58 mannoprotein [97]. Nevertheless an absence of relationship between hypogammaglobulinemia and susceptibility to fungal infections in general (with the exception of case studies) suggests that cellular responses have a major role in the protection against fungal infections and that antibodies might play a supportive role by reducing the fungal burden and by shaping the immune responses. Therefore, further research is warranted to understand the natural antibody responses to fungal pathogens in humans.

As passive administration of specific protective antibodies shown promising results in experimental models, two antibodies have entered clinical trials in recent years.

Patients with cryptococcosis elicit specific antibodies to glucosylceramide and affinity purified these antibodies exhibit inhibitory activity on cell budding and fungal growth of C. neoformans [98]. Human IgM MAb specific to glucuronoxylomannan prolonged survival of $C$. neoformans-infected mice [99]. Based on these experimental

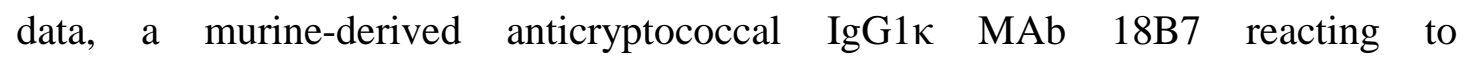
glucuronoxylomannan entered phase I, multi-institution, open-label, nonrandomized, dose-escalation study in HIV-infected subjects who had been successfully treated for cryptococcal meningitis [100]. Preclinical study has demonstrated that MAb 18B7 recognizes all four serotypes of $C$. neoformans, opsonizes $C$. neoformans serotypes A and $\mathrm{D}$, increase the antifungal actions of human and mouse effector cells, and activate the complement pathway leading to deposition of complement $\mathrm{C} 3$ on the capsule of 
Cryptococcus [101]. Also, MAb 18B7 therapy in mice led to quick clearance of serum cryptococcal antigen. Phase I study revealed acceptable safety for this antibody and suggested further investigation at a maximum single dose of $1.0 \mathrm{mg} / \mathrm{kg}$. Cryptococcal antigen titers in the serum of these patients dropped by a median of two-fold at first week and a median of three-fold at two weeks post-therapy. The half-life of the MAb 18B7 in the serum was found to be nearly $53 \mathrm{~h}$. Further randomized clinical trials are awaited for this antibody.

A strong and sustained antibody response to hsp90 was associated with recovery of patients from invasive candidiasis following treatment with amphotericin B [102-104]. An immunodominant epitope on the Hsp90 of C. albicans is present both in filamentaous fungi and in yeasts including C. parapsilosis, Torulopsis glabrata, Candida tropicalis, Candida krusei and A. fumigatus [105]. Therefore, a single-chain variable fragment of a human monoclonal antibody Efungumab (Mycograb®) recognizing immunodominat epitope on the Hsp90 of C. albicans has entered clinical trials in patients with invasive candidiasis. A double-blind, randomized study demonstrated that Efungumab combined with lipid-associated amphotericin B produce significant clinical and culture-confirmed improvement in outcome for patients with invasive candidiasis [106]. A pre-clinical data also supported synergy between Efungumab and caspofungin [107]. However, a recent study suggested that Efungumab potentiation of amphotericin B could be non-specific [108]. Although a status of an orphan drug has been given in USA for this antibody, its use in Europe is not permitted by European Medicines Agency due to potential side effects and concerns about aggregation of the antibody. Also, Novartis discontinued the clinical development of this anti-fungal antibody in 2010. 
Treatment of fungal-mediated inflammatory conditions: quest for unusual savior, intravenous immunoglobulin

Intravenous immunoglobulin (IVIg) is a therapeutic preparation of normal IgG obtained from pooled plasma of several thousand healthy donors. Depending on the exposure of donors to infectious diseases and vaccines and also on the endemic nature of the infectious diseases, IVIg contains antibodies to various pathogens of bacterial, viral, fungal and parasitic origin [40, 109]. In addition, natural antibodies represent major composition of IVIg [110].

Initially used for the replacement therapy of primary and secondary immunodeficiencies, high-dose (1-2 g/kg body weight) IVIg is currently used in the therapy of diverse autoimmune and inflammatory diseases such as Kawasaki disease, Guillain-Barré Syndrome, inflammatory myopathies, immune thrombocytopenic purpura, chronic inflammatory demyelinating polyneuropathy, vasculitis, graft versus host disease, and others as an immunomodulatory agent with no reports of serious side effects [110-115]. In addition to invasive disease, fungi species are also associated with several inflammatory conditions such as both IgE and eosinophiliadriven hypersensitivity diseases including severe asthma, allergic bronchopulmonary mycoses, chronic sinusitis, hypersensitivity pneumonitis, atopic eczema/dermatitis syndrome and gut inflammation. Of note, IVIg has been used as an off label drug in allergy and asthma [116-121] and shown protective effects in experimental models of allergic airway inflammation [122-126].

IVIg could act as immunomodulatory agent in inflammatory conditions via several mutually nonexclusive mechanisms (Fig. 1). Thus, IVIg could inhibit the 
activation of innate cells such as DCs, macrophages, neutrophils, iNKT cells and the secretion of inflammatory cytokines while enhancing the anti-inflammatory mediators such as IL-1RA and IL-10. IVIg inhibits the differentiation and expansion of Th17 cells and reciprocally expands Tregs, regulates the functions of B cells, activation of endothelial cells and their secretion of cytokines and chemokines. In addition, IVIg could neutralize the pathogens including fungi and their antigens [123, 124, 126-143]. This broad range of activities of IVIg reflects the importance of circulating immunoglobulins in the maintenance of immune homeostasis.

In an open-label study with eight severe steroid-dependent asthma children aged between 6 to 17 years, treatment with IVIg (six monthly infusion at $2 \mathrm{~g} / \mathrm{kg}$ ) resulted in significant reductions in steroid requirements. In addition, IVIg therapy led to decrease in serum IgE levels and a progressive diminution in skin test reactivity to allergens [116]. Other anecdotal studies also supported the use of IVIg in severe asthma with a steroid-sparing effect [117, 144-146]. The immunological analysis revealed that IVIg treatment decreased number of activated $\mathrm{CD}^{+}{ }^{-}$cells, $\mathrm{CD}^{+} \mathrm{T}$ cells in endobronchial biopsies with a reduction in peripheral blood $\mathrm{T}$ cell activation, decreased total serum IgE and IL-8 [144]. Also, IVIg could synergistically act with dexamethasone to inhibit lymphocyte activation and improve glucocorticoid receptor binding affinity [117, 147]. A multicenter, randomized, double-blind, placebocontrolled trial of high-dose IVIg although failed to show benefits in corticosteroiddependent asthma [118], this study period was only two months and patients included were over 40 years. Therefore, based on this report, it might be concluded that younger patients probably benefit from IVIg therapy. Also modifications in the immune system due to previous drugs/therapies in adult patients might influence the 
immunomodulatory functions of IVIg. Although further randomized clinical trials are required to support the use of IVIg in asthma and allergy, IVIg is not currently used as a first line therapy due to the availability of several new generation drugs. But these studies and experimental models provided a clue that IVIg could benefits fungal inflammatory conditions.

\section{Conclusion}

Treatment of disseminated fungal infections are still challenging due to costs associated with the treatments, growing reports of antifungal drug resistance, toxicity of anti-fungal drugs and non-availability of protective vaccines. Although, humoral immunity might not have a major role in conferring protection against fungal infections in human, passive administration of specific protective antibodies could prove to be beneficial in drug-resistance cases, to reduce the dosage and associated toxic symptoms of anti-fungal drugs. The longer half-life of the antibodies and flexibilities to modify their structure/forms are additional advantages with anti-fungal antibodies. The clinical data obtained with two antibodies should incite interests in translating pre-clinical success into the clinics. In addition, clinically proven benefits of IVIg in various inflammatory diseases substantiate the necessity of testing this therapeutic preparation in fungal-mediated allergy and inflammatory conditions.

Most of the protective antibodies described to date recognize surface molecules of the fungi. Though "one antibody for all pathogenic fungi” is still elusive, there are experimental evidences that suggest that common cell wall componentspecific protective antibodies like $\beta$-glucan exert protection across the several species of fungi [51, 61]. Another option could be broad-spectrum recombinant single chain 
fragment (ScFv) anti-idiotypic antibodies bearing the internal image of a yeast killer toxin (KT). These killer antibodies are lethal to yeasts and filamentous fungi including C. albicans, A. fumigatus and P. carinii that express specific $\beta-1,3$ D-glucan cell-wall receptor (KTR). These KT-scFv were reported to have fungicidal properties against C. albicans both in vitro and in vivo model of experimental vaginal candidiasis [148]. A decapeptide resulting from the variable region sequence and containing part of the CDR1 segment of the KT-scFv light chain also exerted therapeutic activity against experimental mucosal and systemic candidiasis [149]. Killer anti-idiotypic MAb bearing the internal image of a yeast killer toxin showed protection against early invasive aspergillosis in a murine model of allogenic T-celldepleted bone marrow transplantation [150]. In addition, natural yeast KT-like antibodies with candidacidal properties were also identified in the vaginal fluid of candida infected human vaginitis patients [151]. 


\section{Acknowledgments:}

This study was upported by European Community's Seventh Framework Programme [FP7/2007-2013] under Grant Agreement No: 260338 ALLFUN and ANR-10BLAN-1309 HYDROPHOBIN. We also thank the supports from Institut National de la Santé et de la Recherche Médicale (INSERM), Centre National de la Recherche Scientifique (CNRS), Université Pierre et Marie Curie and Université Paris Descartes. 


\section{References}

1. Romani L (2004) Immunity to fungal infections. Nat Rev Immunol 4:1-23.

2. Romani L (2011) Immunity to fungal infections. Nat Rev Immunol 11:275288.

3. Wuthrich M, Deepe GS, Jr., Klein B (2012) Adaptive immunity to fungi. Annu Rev Immunol 30:115-148.

4. Hube B (2009) Fungal adaptation to the host environment. Curr Opin Microbiol 12:347-349.

5. Cooney NM, Klein BS (2008) Fungal adaptation to the mammalian host: it is a new world, after all. Curr Opin Microbiol 11:511-516.

6. Aimanianda V, Bayry J, Bozza S et al (2009) Surface hydrophobin prevents immune recognition of airborne fungal spores. Nature 460:1117-1121.

7. Bayry J, Aimanianda V, Guijarro JI et al (2012) Hydrophobins--unique fungal proteins. PLoS Pathog 8:e1002700.

8. Jouault T, Sarazin A, Martinez-Esparza M et al (2009) Host responses to a versatile commensal: PAMPs and PRRs interplay leading to tolerance or infection by Candida albicans. Cell Microbiol 11:1007-1015.

9. van de Veerdonk FL, Kullberg BJ, van der Meer JW et al (2008) Hostmicrobe interactions: innate pattern recognition of fungal pathogens. Curr Opin Microbiol 11:305-312.

10. Bourgeois C, Majer O, Frohner IE et al (2010) Fungal attacks on mammalian hosts: pathogen elimination requires sensing and tasting. Curr Opin Microbiol 13:401-408.

11. Bromuro C, Torosantucci A, Chiani P et al (2002) Interplay between protective and inhibitory antibodies dictates the outcome of experimentally disseminated Candidiasis in recipients of a Candida albicans vaccine. Infect Immun 70:5462-5470.

12. Nussbaum G, Yuan R, Casadevall A, Scharff MD (1996) Immunoglobulin G3 blocking antibodies to the fungal pathogen Cryptococcus neoformans. J Exp Med 183:1905-1909.

13. Kuruganti U, Henderson LA, Garner RE et al (1988) Nonspecific and Candida-specific immune responses in mice suppressed by chronic administration of anti-mu. J Leukoc Biol 44:422-433.

14. Han Y, Morrison RP, Cutler JE (1998) A vaccine and monoclonal antibodies that enhance mouse resistance to Candida albicans vaginal infection. Infect Immun 66:5771-5776.

15. Mukherjee J, Scharff MD, Casadevall A (1992) Protective murine monoclonal antibodies to Cryptococcus neoformans. Infect Immun 60:4534-4541

16. Montagnoli C, Bozza S, Bacci A et al (2003) A role for antibodies in the generation of memory antifungal immunity. Eur J Immunol 33:1193-1204.

17. Berland R, Wortis HH (2002) Origins and functions of B-1 cells with notes on the role of CD5. Annu Rev Immunol 20:253-300.

18. Coutinho A, Kazatchkine MD, Avrameas S (1995) Natural autoantibodies. Curr Opin Immunol 7:812-818.

19. Hardy RR (2006) B-1 B cells: development, selection, natural autoantibody and leukemia. Curr Opin Immunol 18:547-555.

20. Kohler H, Bayry J, Nicoletti A et al (2003) Natural autoantibodies as tools to predict the outcome of immune response? Scand J Immunol 58:285-289. 
21. Zhou ZH, Wild T, Xiong $Y$ et al (2013) Polyreactive antibodies plus complement enhance the phagocytosis of cells made apoptotic by UV-light or HIV. Sci Rep 3:2271.

22. Notkins AL (2004) Polyreactivity of antibody molecules. Trends Immunol 25:174-179.

23. Ehrenstein MR, Notley CA (2010) The importance of natural IgM: scavenger, protector and regulator. Nat Rev Immunol 10:778-786.

24. Li W, Fu M, An JG et al (2007) Host defence against C. albicans infections in IgH transgenic mice with $\mathrm{V}(\mathrm{H})$ derived from a natural anti-keratin antibody. Cell Microbiol 9:306-315.

25. Kaveri SV, Silverman GJ, Bayry J (2012) Natural IgM in immune equilibrium and harnessing their therapeutic potential. J Immunol 188:939-945.

26. Tian R, Fu M, Zhang Z et al (2013) In situ IgM production and clonal expansion of B-1 cells in peritoneal cavity promote elimination of C. albicans infection in IgH transgenic mice with $\mathrm{VH}$ derived from a natural antibody. PLoS One 8:e60779.

27. Cassone A, Conti S, De Bernardis F et al (1997) Antibodies, killer toxins and antifungal immunoprotection: a lesson from nature? Immunol Today 18:164169.

28. Matthews R, Burnie J (2001) Antifungal antibodies: a new approach to the treatment of systemic candidiasis. Curr Opin Investig Drugs 2:472-476.

29. Wozniak KL, Wormley FL, Jr., Fidel PL, Jr. (2002) Candida-specific antibodies during experimental vaginal candidiasis in mice. Infect Immun 70:5790-5799.

30. Subramaniam KS, Datta K, Quintero E et al (2010) The absence of serum IgM enhances the susceptibility of mice to pulmonary challenge with Cryptococcus neoformans. J Immunol 184:5755-5767.

31. Rapaka RR, Ricks DM, Alcorn JF et al (2010) Conserved natural IgM antibodies mediate innate and adaptive immunity against the opportunistic fungus Pneumocystis murina. J Exp Med 207:2907-2919.

32. Szymczak WA, Davis MJ, Lundy SK et al (2013) X-linked immunodeficient mice exhibit enhanced susceptibility to Cryptococcus neoformans Infection. mBio 4: e00265-13.

33. Maiti PK, Kumar A, Kumar R et al (1985) Role of antibodies and effect of BCG vaccination in experimental candidiasis in mice. Mycopathologia 91:7985.

34. Cantorna MT, Balish E (1991) Acquired immunity to systemic candidiasis in immunodeficient mice. J Infect Dis 164:936-943.

35. Narayanan R, Joyce WA, Greenfield RA (1991) Gastrointestinal candidiasis in a murine model of severe combined immunodeficiency syndrome. Infect Immun 59:2116-2119.

36. Carrow EW, Hector RF, Domer JE (1984) Immunodeficient CBA/N mice respond effectively to Candida albicans. Clin Immunol Immunopathol 33:371380.

37. Wagner RD, Vazquez-Torres A, Jones-Carson J et al (1996) B cell knockout mice are resistant to mucosal and systemic candidiasis of endogenous origin but susceptible to experimental systemic candidiasis. J Infect Dis 174:589597.

38. Casadevall A, Pirofski LA (2012) Immunoglobulins in defense, pathogenesis, and therapy of fungal diseases. Cell Host Microbe 11:447-456. 
39. Moulin V, Andris F, Thielemans K et al (2000) B lymphocytes regulate dendritic cell (DC) function in vivo: increased interleukin 12 production by DCs from B cell-deficient mice results in T helper cell type 1 deviation. J Exp Med 192:475-482.

40. Bayry J, Lacroix-Desmazes S, Donkova-Petrini V et al (2004) Natural antibodies sustain differentiation and maturation of human dendritic cells. Proc Natl Acad Sci USA 101:14210-14215.

41. Bayry J, Lacroix-Desmazes S, Kazatchkine MD et al (2005) Modulation of dendritic cell maturation and function by B lymphocytes. J Immunol 175:1520.

42. Morva A, Lemoine S, Achour A et al (2012) Maturation and function of human dendritic cells are regulated by B lymphocytes. Blood 119:106-114.

43. Maddur MS, Kaveri SV, Bayry J (2012) Regulation of human dendritic cells by B cells depends on the signals they receive. Blood 119:3863-3864.

44. Berggren O, Hagberg N, Weber G et al (2012) B lymphocytes enhance interferon-alpha production by plasmacytoid dendritic cells. Arthritis Rheum 64:3409-3419.

45. Maddur MS, Kaveri SV, Bayry J (2013) Dual role of CpG-stimulated B cells in the regulation of dendritic cells. Arthritis Rheum 65:2215-2216.

46. Maddur MS, Sharma M, Hegde P, Stephen-Victor E, Pulendran B, Kaveri SV et al (2014) Human B cells induce dendritic cell maturation and favor Th2 polarization by inducing OX-40 ligand. Nature Commun 5:4092.

47. Tristao FS, Panagio LA, Rocha FA et al (2013) B cell-deficient mice display enhanced susceptibility to Paracoccidioides brasiliensis Infection. Mycopathologia 176:1-10.

48. Xin H, Dziadek S, Bundle DR et al (2008) Synthetic glycopeptide vaccines combining beta-mannan and peptide epitopes induce protection against candidiasis. Proc Natl Acad Sci USA 105:13526-13531.

49. Xin H, Cutler JE (2011) Vaccine and monoclonal antibody that enhance mouse resistance to candidiasis. Clin Vaccine Immunol 18:1656-1667.

50. Xin H, Cartmell J, Bailey JJ et al (2012) Self-adjuvanting glycopeptide conjugate vaccine against disseminated candidiasis. PLoS One 7:e35106.

51. Torosantucci A, Bromuro C, Chiani P et al (2005) A novel glyco-conjugate vaccine against fungal pathogens. J Exp Med 202:597-606.

52. Torosantucci A, Chiani P, Bromuro C et al (2009) Protection by anti-betaglucan antibodies is associated with restricted beta-1,3 glucan binding specificity and inhibition of fungal growth and adherence. PLoS One 4:e5392.

53. Sandini S, La Valle R, Deaglio S et al (2011) A highly immunogenic recombinant and truncated protein of the secreted aspartic proteases family (rSap2t) of Candida albicans as a mucosal anticandidal vaccine. FEMS Immunol Med Microbiol 62:215-224.

54. De Bernardis F, Amacker M, Arancia S et al (2012) A virosomal vaccine against candidal vaginitis: immunogenicity, efficacy and safety profile in animal models. Vaccine 30:4490-4498.

55. Theus SA, Smulian AG, Steele P et al (1998) Immunization with the major surface glycoprotein of Pneumocystis carinii elicits a protective response. Vaccine 16:1149-1157.

56. Zheng M, Ramsay AJ, Robichaux MB et al (2005) CD4+ T cell-independent DNA vaccination against opportunistic infections. J Clin Invest 115:35363544. 
57. Zheng M, Shellito JE, Marrero L et al (2001) CD4+ T cell-independent vaccination against Pneumocystis carinii in mice. J Clin Invest 108:14691474.

58. Rosas AL, Nosanchuk JD, Casadevall A (2001) Passive immunization with melanin-binding monoclonal antibodies prolongs survival of mice with lethal Cryptococcus neoformans infection. Infect Immun 69:3410-3412.

59. Dromer F, Charreire J, Contrepois A et al (1987) Protection of mice against experimental cryptococcosis by anti-Cryptococcus neoformans monoclonal antibody. Infect Immun 55:749-752.

60. Rodrigues ML, Shi L, Barreto-Bergter E et al (2007) Monoclonal antibody to fungal glucosylceramide protects mice against lethal Cryptococcus neoformans infection. Clin Vaccine Immunol 14:1372-1376.

61. Rachini A, Pietrella D, Lupo P et al (2007) An anti-beta-glucan monoclonal antibody inhibits growth and capsule formation of Cryptococcus neoformans in vitro and exerts therapeutic, anticryptococcal activity in vivo. . Infect Immun 75:5085-5094.

62. Yuan R, Casadevall A, Spira G et al (1995) Isotype switching from IgG3 to IgG1 converts a nonprotective murine antibody to Cryptococcus neoformans into a protective antibody. J Immunol 154:1810-1816.

63. Yuan RR, Spira G, Oh J et al (1998) Isotype switching increases efficacy of antibody protection against Cryptococcus neoformans infection in mice. Infect Immun 66:1057-1062.

64. Beenhouwer DO, Shapiro S, Feldmesser M et al (2001) Both Th1 and Th2 cytokines affect the ability of monoclonal antibodies to protect mice against Cryptococcus neoformans. Infect Immun 69:6445-6455.

65. Rivera J, Mukherjee J, Weiss LM et al (2002) Antibody efficacy in murine pulmonary Cryptococcus neoformans infection: a role for nitric oxide. $\mathrm{J}$ Immunol 168:3419-3427.

66. McClelland EE, Nicola AM, Prados-Rosales R et al (2010) Ab binding alters gene expression in Cryptococcus neoformans and directly modulates fungal metabolism. J Clin Invest 120:1355-1361.

67. Shapiro S, Beenhouwer DO, Feldmesser M et al (2002) Immunoglobulin G monoclonal antibodies to Cryptococcus neoformans protect mice deficient in complement component C3. Infect Immun 70:2598-2604.

68. Rivera J, Casadevall A (2005) Mouse genetic background is a major determinant of isotype-related differences for antibody-mediated protective efficacy against Cryptococcus neoformans. J Immunol 174:8017-8026.

69. Nussbaum G, Cleare W, Casadevall A et al (1997) Epitope location in the Cryptococcus neoformans capsule is a determinant of antibody efficacy. J Exp Med 185:685-694.

70. Han Y, Cutler JE (1995) Antibody response that protects against disseminated candidiasis. Infect Immun 63:2714-2719.

71. Han Y, Cutler JE (1997) Assessment of a mouse model of neutropenia and the effect of an anti-candidiasis monoclonal antibody in these animals. J Infect Dis 175:1169-1175.

72. Han Y, Riesselman MH, Cutler JE (2000) Protection against candidiasis by an immunoglobulin G3 (IgG3) monoclonal antibody specific for the same mannotriose as an IgM protective antibody. Infect Immun 68:1649-1654.

73. Johnson MA, Cartmell J, Weisser NE et al (2012) Molecular recognition of Candida albicans (1-2)-beta-mannan oligosaccharides by a protective 
monoclonal antibody reveals the immunodominance of internal saccharide residues. J Biol Chem 287:18078-18090.

74. Han Y (2010) Efficacy of combination immunotherapy of IgM MAb B6.1 and amphotericin B against disseminated candidiasis. Int Immunopharmacol 10:1526-1531.

75. Han Y, Kozel TR, Zhang MX et al (2001) Complement is essential for protection by an IgM and an IgG3 monoclonal antibody against experimental, hematogenously disseminated candidiasis. J Immunol 167:1550-1557.

76. Caesar-TonThat TC, Cutler JE (1997) A monoclonal antibody to Candida albicans enhances mouse neutrophil candidacidal activity. Infect Immun 65:5354-5357.

77. Moragues MD, Omaetxebarria MJ, Elguezabal N et al (2003) A monoclonal antibody directed against a Candida albicans cell wall mannoprotein exerts three anti-C. albicans activities. Infect Immun 71:5273-5279.

78. Brena S, Cabezas-Olcoz J, Moragues MD et al (2011) Fungicidal monoclonal antibody C7 interferes with iron acquisition in Candida albicans. Antimicrob Agents Chemother 55:3156-3163.

79. Chaturvedi AK, Kavishwar A, Shiva Keshava GB et al (2005) Monoclonal immunoglobulin G1 directed against Aspergillus fumigatus cell wall glycoprotein protects against experimental murine aspergillosis. Clin Diag Lab Immunol 12:1063-1068.

80. Chaturvedi AK, Kumar R, Kumar A et al (2009) A monoclonal IgM directed against immunodominant catalase $\mathrm{B}$ of cell wall of Aspergillus fumigatus exerts anti-A. fumigatus activities. Mycoses 52:524-533.

81. Appel E, Vallon-Eberhard A, Rabinkov A et al (2010) Therapy of murine pulmonary aspergillosis with antibody-alliinase conjugates and alliin. Antimicrob Agents Chemother 54:898-906.

82. Buissa-Filho R, Puccia R, Marques AF et al (2008) The monoclonal antibody against the major diagnostic antigen of Paracoccidioides brasiliensis mediates immune protection in infected BALB/c mice challenged intratracheally with the fungus. Infect Immun 76:3321-3328.

83. Gigliotti F, Haidaris CG, Wright TW et al (2002) Passive intranasal monoclonal antibody prophylaxis against murine Pneumocystis carinii pneumonia. Infect Immun 70:1069-1074.

84. Wells J, Haidaris CG, Wright TW et al (2006) Complement and Fc function are required for optimal antibody prophylaxis against Pneumocystis carinii pneumonia. Infect Immun 74:390-393.

85. Nosanchuk JD, Steenbergen JN, Shi L et al (2003) Antibodies to a cell surface histone-like protein protect against Histoplasma capsulatum. J Clin Invest 112:1164-1175.

86. Shi L, Albuquerque PC, Lazar-Molnar E et al (2008) A monoclonal antibody to Histoplasma capsulatum alters the intracellular fate of the fungus in murine macrophages. Eukaryot Cell 7:1109-1117.

87. Guimaraes AJ, Frases S, Gomez FJ et al (2009) Monoclonal antibodies to heat shock protein 60 alter the pathogenesis of Histoplasma capsulatum. Infect Immun 77:1357-1367.

88. Zhang MX, Lupan DM, Kozel TR (1997) Mannan-specific immunoglobulin G antibodies in normal human serum mediate classical pathway initiation of C3 binding to Candida albicans. Infect Immun 65:3822-3827. 
89. Kozel TR, MacGill RS, Percival A et al (2004) Biological activities of naturally occurring antibodies reactive with Candida albicans mannan. Infect Immun 72:209-218.

90. Zhang MX, Bohlman MC, Itatani C et al (2006) Human recombinant antimannan immunoglobulin G1 antibody confers resistance to hematogenously disseminated candidiasis in mice. Infect Immun 74:362-369.

91. Boxx GM, Nishiya CT, Kozel TR et al (2009) Characteristics of Fcindependent human antimannan antibody-mediated alternative pathway initiation of C3 deposition to Candida albicans. Mol Immunol 46:473-480.

92. Calcedo R, Ramirez-Garcia A, Abad A et al (2012) Phosphoglycerate kinase and fructose bisphosphate aldolase of Candida albicans as new antigens recognized by human salivary IgA. Rev Iberoam Micol 29:172-174.

93. van der Velden WJ, Blijlevens NM, Klont RR et al (2006) Primary hepatic invasive aspergillosis with progression after rituximab therapy for a post transplantation lymphoproliferative disorder. Ann Hematol 85:621-623.

94. Gil L, Kozlowska-Skrzypczak M, Mol A et al (2009) Increased risk for invasive aspergillosis in patients with lymphoproliferative diseases after autologous hematopoietic SCT. Bone Marrow Transplant 43:121-126.

95. Goldman DL, Khine H, Abadi J et al (2001) Serologic evidence for Cryptococcus neoformans infection in early childhood. Pediatrics 107:E66.

96. Pitarch A, Nombela C, Gil C (2011) Prediction of the clinical outcome in invasive candidiasis patients based on molecular fingerprints of five antiCandida antibodies in serum. Mol Cell Proteomics 10:M110 004010.

97. Viudes A, Lazzell A, Perea S et al (2004) The C-terminal antibody binding domain of Candida albicans mp58 represents a protective epitope during candidiasis. FEMS Microbiol Lett 232:133-138.

98. Rodrigues ML, Travassos LR, Miranda KR et al (2000) Human antibodies against a purified glucosylceramide from Cryptococcus neoformans inhibit cell budding and fungal growth. Infect Immun 68:7049-7060.

99. Fleuridor R, Zhong Z, Pirofski L (1998) A human IgM monoclonal antibody prolongs survival of mice with lethal cryptococcosis. J Infect Dis 178:12131216.

100. Larsen RA, Pappas PG, Perfect J et al (2005) Phase I evaluation of the safety and pharmacokinetics of murine-derived anticryptococcal antibody $18 \mathrm{~B} 7$ in subjects with treated cryptococcal meningitis. Antimicrob Agents Chemother 49:952-958.

101. Casadevall A, Cleare W, Feldmesser M et al (1998) Characterization of a murine monoclonal antibody to Cryptococcus neoformans polysaccharide that is a candidate for human therapeutic studies. Antimicrob Agents Chemother 42:1437-1446.

102. Matthews RC, Burnie JP, Tabaqchali S (1984) Immunoblot analysis of the serological response in systemic candidosis. Lancet 2:1415-1418.

103. Matthews RC, Burnie JP, Tabaqchali S (1987) Isolation of immunodominant antigens from sera of patients with systemic candidiasis and characterization of serological response to Candida albicans. J Clin Microbiol 25:230-237.

104. Swoboda RK, Bertram G, Budge S et al (1995) Structure and regulation of the HSP90 gene from the pathogenic fungus Candida albicans. Infect Immun 63:4506-4514.

105. Matthews RC, Burnie JP (2004) Recombinant antibodies: a natural partner in combinatorial antifungal therapy. Vaccine 22:865-871. 
106. Pachl J, Svoboda P, Jacobs F et al (2006) A randomized, blinded, multicenter trial of lipid-associated amphotericin B alone versus in combination with an antibody-based inhibitor of heat shock protein 90 in patients with invasive candidiasis. Clin Infect Dis 42:1404-1413.

107. Hodgetts S, Nooney L, Al-Akeel R et al (2008) Efungumab and caspofungin: pre-clinical data supporting synergy. J Antimicrob Chemother 61:1132-1139.

108. Richie DL, Ghannoum MA, Isham N et al (2012) Nonspecific effect of Mycograb on amphotericin B MIC. Antimicrob Agents Chemother 56:39633964.

109. Krause I, Wu R, Sherer Y et al (2002) In vitro antiviral and antibacterial activity of commercial intravenous immunoglobulin preparations--a potential role for adjuvant intravenous immunoglobulin therapy in infectious diseases. Transfus Med 12:133-139.

110. Kazatchkine MD, Kaveri SV (2001) Immunomodulation of autoimmune and inflammatory diseases with intravenous immune globulin. $\mathrm{N}$ Engl $\mathrm{J}$ Med 345:747-755.

111. Kaveri SV, Maddur MS, Hegde P et al (2011) Intravenous immunoglobulins in immunodeficiencies: more than mere replacement therapy. Clin Exp Immunol 164:2-5.

112. Negi VS, Elluru S, Siberil S et al (2007) Intravenous immunoglobulin: an update on the clinical use and mechanisms of action. J Clin Immunol 27:233245.

113. Bayry J, Negi VS, Kaveri SV (2011) Intravenous immunoglobulin therapy in rheumatic diseases. Nat Rev Rheumatol 7:349-359.

114. Dalakas MC (2004) Intravenous immunoglobulin in autoimmune neuromuscular diseases. JAMA 291:2367-2375.

115. Nussinovitch U, Shoenfeld Y (2008) Intravenous immunoglobulin indications and mechanisms in cardiovascular diseases. Autoimmun Rev 7:445-452.

116. Mazer BD, Gelfand EW (1991) An open-label study of high-dose intravenous immunoglobulin in severe childhood asthma. J Allergy Clin Immunol 87:976-983.

117. Spahn JD, Leung DY, Chan MT et al (1999) Mechanisms of glucocorticoid reduction in asthmatic subjects treated with intravenous immunoglobulin. J Allergy Clin Immunol 103:421-426.

118. Kishiyama JL, Valacer D, Cunningham-Rundles C et al (1999) A multicenter, randomized, double-blind, placebo-controlled trial of high-dose intravenous immunoglobulin for oral corticosteroid-dependent asthma. Clin Immunol 91:126-133.

119. Salmun LM, Barlan I, Wolf HM et al (1999) Effect of intravenous immunoglobulin on steroid consumption in patients with severe asthma: a double-blind, placebo-controlled, randomized trial. J Allergy Clin Immunol 103:810-815.

120. Toledo F, Silvestre JF, Munoz C (2012) Combined therapy with low-dose omalizumab and intravenous immunoglobulin for severe atopic dermatitis. Report of four cases. J Eur Acad Dermatol Venereol 26:1325-1327.

121. Turner PJ, Kakakios A, Wong LC et al (2012) Intravenous immunoglobulin to treat severe atopic dermatitis in children: a case series. Pediatr Dermatol 29:177-181. 
122. Kaufman GN, Massoud AH, Audusseau S et al (2011) Intravenous immunoglobulin attenuates airway hyperresponsiveness in a murine model of allergic asthma. Clin Exp Allergy 41:718-28.

123. Massoud AH, Guay J, Shalaby KH et al (2012) Intravenous immunoglobulin attenuates airway inflammation through induction of forkhead box protein 3positive regulatory T cells. J Allergy Clin Immunol 129:1656-1665.

124. Araujo LM, Chauvineau A, Zhu R et al (2011) Cutting edge: intravenous Ig inhibits invariant NKT cell-mediated allergic airway inflammation through FcgammaRIIIA-dependent mechanisms. J Immunol 186:3289-3293.

125. Batard T, Zimmer A, Nony E et al (2012) Anti-inflammatory activity of sublingual immunoglobulin (SLIG) in a murine model of allergen-driven airway inflammation. Vaccine 30:5666-5674.

126. Massoud AH, Yona M, Xue D et al (2014) Dendritic cell immunoreceptor: a novel receptor for intravenous immunoglobulin mediates induction of regulatory T cells. J Allergy Clin Immunol 133:853-863.

127. Kaneko Y, Nimmerjahn F, Ravetch JV (2006) Anti-inflammatory activity of immunoglobulin G resulting from Fc sialylation. Science 313:670-673.

128. Tha-In T, Bayry J, Metselaar HJ et al (2008) Modulation of the cellular immune system by intravenous immunoglobulin. Trends in immunology 29:608-615.

129. Bayry J, Lacroix-Desmazes S, Carbonneil C et al (2003) Inhibition of maturation and function of dendritic cells by intravenous immunoglobulin. Blood 101:758-765.

130. Seite JF, Shoenfeld Y, Youinou P et al (2008) What is the contents of the magic draft IVIg? Autoimmun Rev 7:435-439.

131. Ballow M (2011) The IgG molecule as a biological immune response modifier: Mechanisms of action of intravenous immune serum globulin in autoimmune and inflammatory disorders. J Allergy Clin Immunol 127:315323.

132. Maddur MS, Kaveri SV, Bayry J (2011) Comparison of different IVIg preparations on IL-17 production by human Th17 cells. Autoimmun Rev 10:809-810.

133. Maddur MS, Hegde P, Sharma M et al (2011) B cells are resistant to immunomodulation by 'IVIg-educated' dendritic cells. Autoimmun Rev 11:154-156.

134. Aubin E, Lemieux R, Bazin R (2010) Indirect inhibition of in vivo and in vitro T-cell responses by intravenous immunoglobulins due to impaired antigen presentation. Blood 115:1727-1734.

135. Maddur MS, Vani J, Hegde P et al (2011) Inhibition of differentiation, amplification, and function of human TH17 cells by intravenous immunoglobulin. J Allergy Clin Immunol 127:823-830.

136. Othy S, Hegde P, Topcu S et al (2013) Intravenous gammaglobulin inhibits encephalitogenic potential of pathogenic $\mathrm{T}$ cells and interferes with their trafficking to the central nervous system, implicating sphingosine-1 phosphate receptor 1-mammalian target of rapamycin axis. J Immunol 190:4535-4541.

137. Ramakrishna C, Newo AN, Shen YW et al (2011) Passively administered pooled human immunoglobulins exert IL-10 dependent anti-inflammatory effects that protect against fatal HSV encephalitis. PLoS Pathog 7:e1002071. 
138. Trinath J, Hegde P, Sharma $M$ et al (2013) Intravenous immunoglobulin expands regulatory $\mathrm{T}$ cells via induction of cyclooxygenase-2-dependent prostaglandin E2 in human dendritic cells. Blood 122:1419-1427.

139. Schwab I, Nimmerjahn F (2013) Intravenous immunoglobulin therapy: how does IgG modulate the immune system? Nat Rev Immunol 13:176-189.

140. Seite JF, Goutsmedt C, Youinou P et al (2014) Intravenous immunoglobulin induces a functional silencing program similar to anergy in human B cells. J Allergy Clin Immunol 133:181-188 e181-189.

141. Casulli S, Topcu S, Fattoum L et al (2011) A differential concentrationdependent effect of IVIg on neutrophil functions: relevance for anti-microbial and anti-inflammatory mechanisms. PLoS One 6:e26469.

142. Semple JW, Kim M, Hou J et al (2012) Intravenous immunoglobulin prevents murine antibody-mediated acute lung injury at the level of neutrophil reactive oxygen species (ROS) production. PLoS One 7:e31357.

143. von Gunten S, Vogel M, Schaub A et al (2007) Intravenous immunoglobulin preparations contain anti-Siglec-8 autoantibodies. J Allergy Clin Immunol 119:1005-1011.

144. Vrugt B, Wilson S, van Velzen E et al (1997) Effects of high dose intravenous immunoglobulin in two severe corticosteroid insensitive asthmatic patients. Thorax 52:662-664.

145. Jakobsson T, Croner S, Kjellman NI et al (1994) Slight steroid-sparing effect of intravenous immunoglobulin in children and adolescents with moderately severe bronchial asthma. Allergy 49:413-420.

146. Landwehr LP, Jeppson JD, Katlan MG et al(1998) Benefits of high-dose i.v. immunoglobulin in patients with severe steroid-dependent asthma. Chest 114:1349-1356.

147. Pashov A, Delignat S, Bayry J et al (2011) Enhancement of the affinity of glucocorticoid receptors as a mechanism underlying the steroid-sparing effect of intravenous immunoglobulin. J Rheumatol 38:2275.

148. Magliani W, Conti S, de Bernardis et al (1997) Therapeutic potential of antiidiotypic single chain antibodies with yeast killer toxin activity. Nat Biotechnol 15:155-158.

149. Polonelli L, Magliani W, Conti S et al (2003) Therapeutic activity of an engineered synthetic killer antiidiotypic antibody fragment against experimental mucosal and systemic candidiasis. Infect Immun 71:6205-6212.

150. Cenci E, Mencacci A, Spreca A et al (2002) Protection of killer antiidiotypic antibodies against early invasive aspergillosis in a murine model of allogeneic T-cell-depleted bone marrow transplantation. Infect Immun 70:2375-2382.

151. Polonelli L, De Bernadis F, Conti S et al (1996) Human natural yeast killer toxin-like candidacidal antibodies. J Immunol 156:1880-1885. 


\section{Figure Legend:}

Fig. 1. Multi-faceted functions of antibodies in the protection against fungal infections and fungi-mediated inflammatory conditions. Antibodies confer protection against fungal infections by multiple mechanisms that include direct neutralization of fungi and their antigens, inhibition of growth of fungi, modification of gene expression, signaling and lipid metabolism, causing iron starvation, inhibition of polysaccharide release and biofilm formation. Antibodies promote opsonization of fungi and their phagocytosis, complement activation and antibody-dependent cell toxicity. Growing evidences also indicate that antibodies have a key role in immunomodulation and in preventing inflammation-mediated tissue damage.

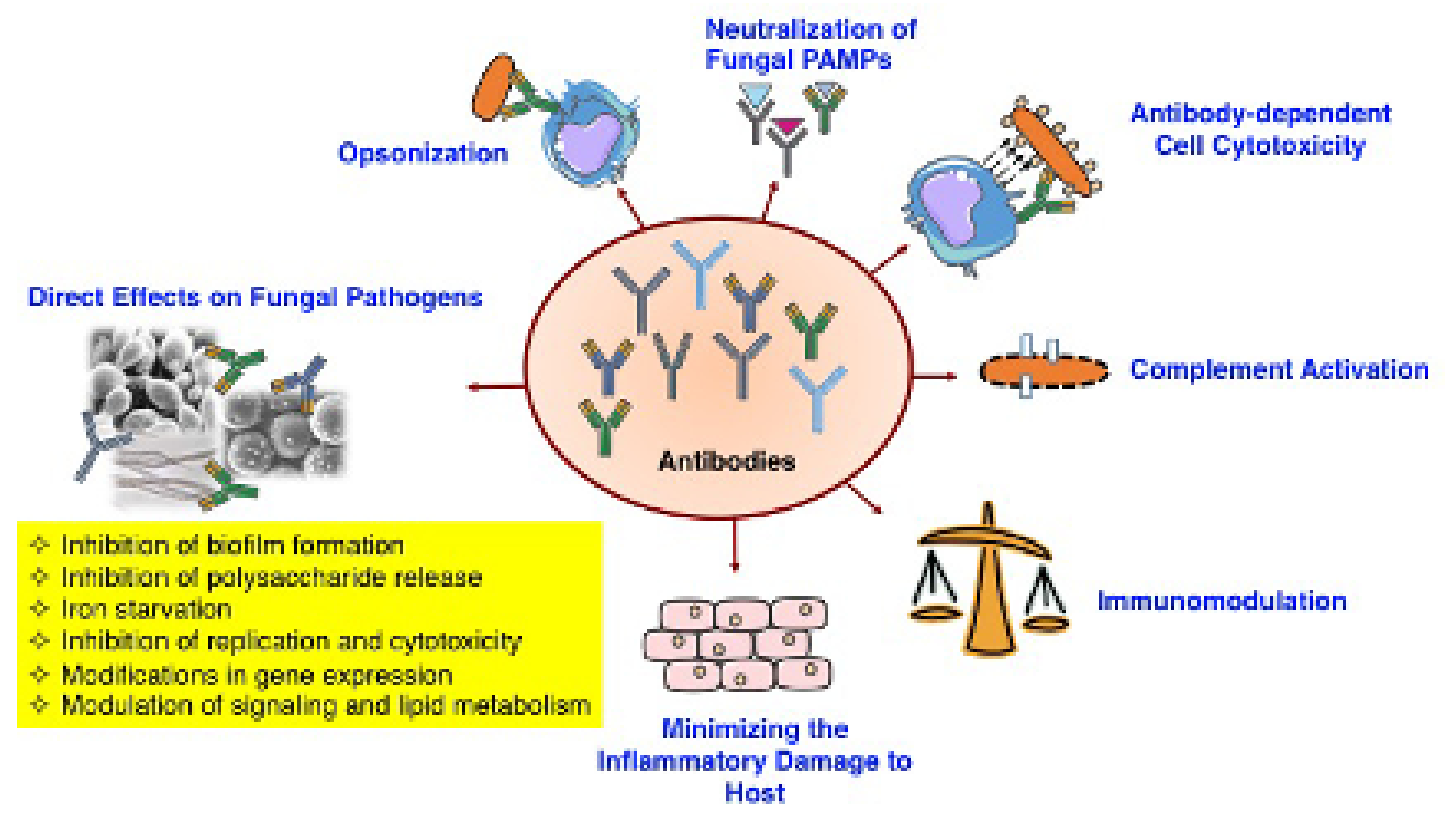

